\title{
JEAN B DAUSSET, 19 OCTOBER 1916-6 JUNE 2009
}

\author{
European Journal of Human Genetics (2009) 17, 1365-1366; doi:10.1038/ejhg.2009.150
}

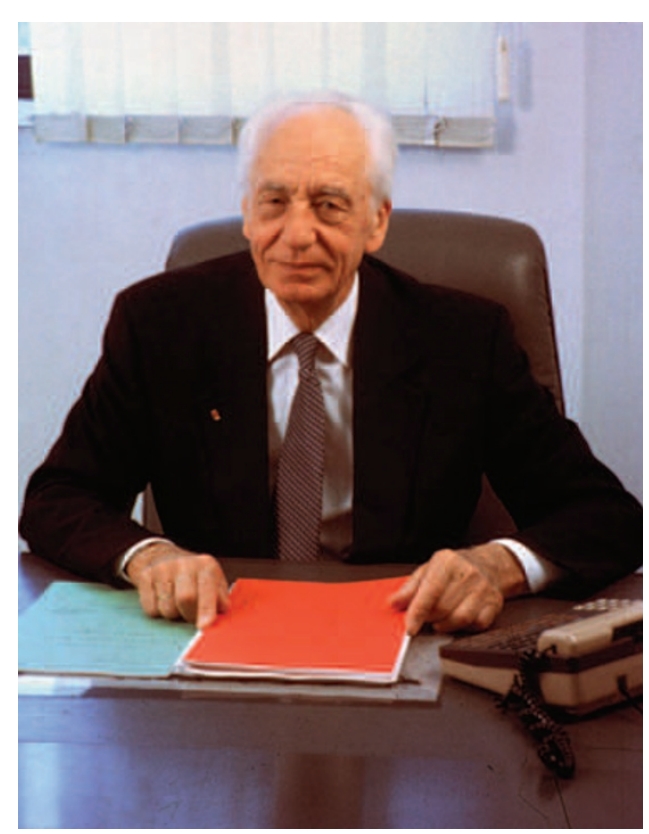

Professor Jean B Dausset, who shared The Nobel Prize in Physiology or Medicine, 1980, with Professors George D Snell and Baruj Benacerraf for his discovery and development of the human major histocompatibility complex (MHC, also commonly called HLA), died in Mallorca, Spain, on 6 June 2009. He was 92 years old. The landmark discoveries of Professor Dausset include agglutination of white blood cells by antibodies from patients who had received blood transfusions, which he realized was due to genetic variation, description of the first leukocyte antigen (now known as HLA-2) and of the first tissue group system (Hu-1, later named HLA), and correlation between graft survival and tissue incompatibility, which was the result of working with volunteer skin donors and recipients. He was active in finding associations of HLA with complex diseases. He was keen on using DNA polymorphisms to characterize HLA. Professors Dausset and E Carosella collaborated in research into the role of HLA-G in human physiology, with implications for immune tolerance in general and pregnancy in particular. Professor Dausset understood the importance of research collaboration and was a dedicated, leading spirit in the HLA Workshops and
Conferences, in which competitors collaborate by typing shared tissue resources. Professor Dausset's research achievements were fundamental for the development of tissue typing, which improved the quality of clinical transplantation. He contributed even more to this field by founding France Transplant and France Greffe de Moelle, organizations that are dedicated to bringing donor organs and bone marrow to needy recipients in an efficient and rapid manner.

In 1984, Professor Dausset created the Centre d'Etude du Polymorphisme Humain (CEPH), a laboratory, later an internationally renowned genome center, which coordinated the first international genome-mapping collaboration by making available DNA from 40 large reference families (later 61) to researchers throughout the world. By genotyping DNA from the same set of families, it was possible to map the human genome by linkage which determined order of DNA markers along all autosomes, the $\mathrm{X}$ chromosome and the $\mathrm{X}-\mathrm{Y}$ pseudoautosomal region. Knowledge of these chromosome maps, which was made available to the scientific community worldwide, permitted researchers, some of them at the CEPH, to localize the major genes for various genetic disorders to regions of the human genome. Localization of such genes was the first, important step in cloning and identifying them, which was a breakthrough for medical genetics. Furthermore, the linkage maps provided the foundation for the International Genome Project, the physical mapping of the human genome (largely initiated at CEPH), which in turn led to determination of the DNA sequence. The CEPH reference families continue to be used for genomics research. More recently, Professor Dausset collaborated with Professor LL Cavalli-Sforza in developing, at the Foundation, a widely used DNA resource from world populations for research in human population genetics, the HGDP-CEPH Diversity Panel. In 1993, the CEPH became the Foundation Jean Dausset - CEPH, a nonprofit research institute funded in part by the Republic of France. Professor Dausset retired as President of the Foundation in 2003; he remained its honorary President until his death.

Professor Dausset was a member of the French National Academy of Sciences, professor at the College de France, a foreign member of the National Academy of Sciences, USA, an honorary member of the American Academy of Arts 
and Sciences, and a member of the founding Council and Vice President of the Human Genome Organization. He received various prestigious prizes, such as the Landsteiner Award and prizes from the Koch and Wolf Foundations. He served on the advisory boards of numerous research institutions.

A CEPH collaborator wrote in a tribute to Professor Dausset, 'He set a standard for cooperative sharing in science with the goal of helping others that has truly revolutionized the ways in which we do our work. All of the genome sharing efforts of sequence and SNPs is based on his CEPH model. It's really not possible to even measure the impact this has had on science.'

Jean-Louis Mandel ${ }^{1}$, Mark Lathrop ${ }^{1}$ and Howard M Cann ${ }^{1}$ ${ }^{1}$ Fondation Jean Dausset - Centre d'Etude du Polymorphisme Humaine (CEPH), 27, rue Juliette Dodu, 75010 Paris, France E-mail: howard@cephb.fr 